\title{
Conference Programme
}

\section{Thursday November 23rd}

T1 Collecting and Calculating Medical Data via the Internet - Workshop Remote Data Entry (RDE): Designing and Implementing Solutions for Your Medical Business

By M. Egbring, G. Hindricks, H. Kottkamp, C. Elsner

T2 How to Create Dynamic Interactive Medical Web Applications

By A. Robert, M.D. Pretlow

T3 Qualité de l'Information Médicale sur Internet

By M. Jamoulle

T4 Internet and Human Genetics

By G. Bottu, V. Ledent (Belgian EMBnet Node)

T5 Security, Electronic Signatures and Pseudonymisation Services

By F. De Meyer

Hospital Intranet Development

T6

$$
\text { By T. Fiers }
$$

XML

By T. Arvanitis

\section{Friday November 24th}

Keynote 1:

Helga Rippen: A Global eHealth Code of Ethics: Vision and Challenges

Oral 1: Clinical Applications 1

op06 IRIS: An Internet Based 3D Radiotherapy Planning and Information System

A. Lüttgau, M.A. Keller-Reichenbecher, W. Schlegel, R. Bendl

op22 Patient E-Care: Present and Future Applications

A. Robert, M.D. Pretlow

op44 Data Driven WAP Applications for Medical Information Handling

J. Dørup, M. Schacht Hansen

op29 Synchronized Rendering of Multimedia Radiological Information: Development of an Internet-Based Application

R. Van de Walle, B. Rogge, I. Lemahieu

op30 A Platform-Independent Datamining / Quality-Management-System with PHP3 and mySQL: a Project Study M. Egbring, S. Grafe, G. Hindricks, H. Kottkamp, C. Elsner

op76 Advanced Information Management for Health Care in Regional Context Using

Reference Models and Internet Technology

G. von der Weiden, M. Haischer, A. Weisbecker 
Oral 2: Telemedicine 1

op59 The UK Telemedicine Information Service J.S. Briggs, A.K. Francis, K.A. Smith, R.G. Curry, B. Madge

op05 EU-TeleInViVo: 3D Ultrasound Telemedical Portable Workstation G. Kontaxakis, S. Walter, G. Sakas

op12 An Intranet-Extranet Telematic System for Women and Gynecologists A. Starita, K. Cerbioni, E. Palanca, D. Majidi, R. Fontanelli

op41 Design and Development of a Web-Based System for Early Recognition and Monitoring of the Diabetic Retinopathy P. Ladyzynski, J.M. Wojcicki, K. Chihara

op49 INCAS: a Telemedicine Network for Multi-Diagnosis Consultation Services C. Colombo, A. Castelli, B. Salvatore, A. Lesma, N. Dal Degan

op53 Security Considerations on the Development of an Internet-Based Infrastructure for Telepathology: the Approach of the Italian Network of Telepathology for Research, Education and Quality Control V. Della Mea, V. Roberto, F. Barbarino, C.A. Beltrami

Keynote 2:

Ilias Iakovidis: From Medical Records to Personal Health Records: The Critical Role of Internet on the Road to Citizen Centered Care

Oral 3: Medical Education

op09 From Satellite to Web: a CME Case Study

H.L. Young

op28 Creating Resources for e-Learning in French Medical Universities

F. Le Duff, A. Fresnel, G. Herengt, J.M. Brunetaud, G. Chatellier, S. Darmoni, P. Gillois, D. Pagonis, G. Soula, M. Spector, P. Le Beux

op34 Automatic Management of Uniform Resources Locators for Medical Training S. Ducamp, F. Le Duff, B. Pouliquen, A. Fresnel, A. Burgun, P. Le Beux

op37 ICT in the Education of Medicine: Conclusions of the Inquiry H. Buysse, A. Derese, G. De Moor

op67 An XML and Ontology Based Methodology and Authoring Environment for Medical Information Systems

D. Roesner, U. Duerer, H.-D. Esperer, A. Moore, G. Parr, M. Logan, K. Zieger

op74 WebSET: Integrated XML and VR Components for Collaborative Medical Training on the Web

A. Emmen, N. John, L. Versweyveld

op84 Improvement of Diagnostic Accuracy by Use of a New Software System and Distribution of Visual Expert Knowledge via the Internet J. Meyrowitsch, M. Høier-Madsen, C. Ingwersen, P. Charles, J. Forslid, A. Wiik

Evidence Based Medicine

op95 Building Web-Enabled Drug Information Centers with Traditional Word Processors, Markup Language, Telematics Standards and Controlled Thesauri R.H. Vander Stichele, J. Van Campen, A. Attipoe, G. Thienpont 
op79 CE-Net - UBHT's Intranet Portal to Support Evidence-Based Medicine in a Large NHS Trust

J. Osborne, M. Palmer

op21 Evidence-Based On-call

C. Ball, R. Phillips

Oral 4: Epidemiology, Security and Impact

op04 The Epidemiological and Territorial Health Information Can Support Strategic Decision R. Benardon

op57 Intra/Extranet System for Clinical and Epidemiological Studies

op63 Constraints on the Free Flow of Information about Outbreaks on the Internet: the ProMED-mail Experience J. Woodall, C.H. Calisher

op91 Towards Internet-Based Epidemiology: Integration of Distributed and Heterogeneous Clinical Data Sources

G. Potamias, C. Christofis, M. Tsiknakis, S. Orphanoudakis

Security

op14 Development of a High Level Security Policy (HLSP) for the Processing of Medical

Data and their Transmission through the Internet

C. Ilioudis, G. Pangalos

op17 Using Digital Certificates for Access Control in Clinical Intranet Applications

I. Mavridis, C. Georgiadis, G. Pangalos, M. Khair

Impact

op18 Reading Factor as a Credible Alternative to Impact Factor: a Preliminary Study

S.J. Darmoni, F. Roussel, J. Benichou, G.C. Faure, B. Thirion, N. Pinhas

Quality of information on the Web

Workshop: E-Content: The Challenge to Provide Quality Health Information

G. Eysenbach

Posters 1:

po64 Online Questionnaire COUGH

K. Dmitriev, K. Adojaan, J. Aru, K. Sergejeva

po86 Clinical Quality Guidelines in a Lotus Notes Based Intranet

C. Bobrowski, G. Kreymann, H. Greten

po87 Use of the Inernet Technologies - Important Tool of Research Work

A. Karas, I. Mathes

po11 Numerical Taxonomy Methods in Telemedicine

T. Postelnicu

po54 The Study of the Net Management of the Computer Digital College and Back-Writing CT or MRI Image in the Application of Clinic and Remote Consultation

po26 Bayes Diagnostic Model on the Internet

B. Kanagaratnam 
Posters 2:

po45 Are we Ready for Internet-Based Teaching of Medicine?

S. Linn, I. Leijbkowitz

po48 Health Care Information Systematization in the Health Secretary of Buenos Aires City Government and Health Information Accessibility Improvement for the Inhabitants by the Application of a Interactive Health Communication (IHC) Program

A. Cacherosky, A. Schiavoni, E. Litera, P. Bonazzola, L. Licciardi

po27 Web Pages as Standard Communication System with Medical Students

M. Petrovecki, L. Bilic-Zulle

po42 Construction of a Web-Based Knowledge Database for Nuclear Medicine

J. Versijpt, C. Bekaert, E. Nolf, F. Jacobs, R.A. Dierckx

po46 A Telematic System for Learning

L. Garelli, M. Bisconcin, G. Maso, M. Pucci, J. Goedhuys, C. Geens, N. Mathers,

R. Glendenning

po47 Quizmaker: a Simple Way to Make Online Questionnaires

L. Garelli, M. Bisconcin, G. Maso, M. Pucci, G. Filocamo

po68 Preventive Medicine / Interactive, Internet-Supported CD-ROM for Non Health Care Professionals (W.I.P.)

B. Daled-Rosseel, L. Lambrecht, E. Macken, A. De Wash, M. Vanbellinghen

po56 MyPACS: a Simple Web-Based Radiological Image Management System B.K. Szabo

po83 A WEB System Achitecture to Support Medical Teaching at University A.K. Barbosa, R. Belian, M. Novaes

po90 Internet as a Tool for Guideline Development J.J. van Croonenborg, C.J.G.M. Rosenbrand, D.J.B. Vermeij

po02 Internet Technology: Proven Strategies that Solidify the Patient-Physician Partnership and Improve Patient Health Outcomes A. Rose

Po08 Use of the Internet in Medicine

D. Siebrecht, H. Lax, W. Popp, M. Ruenzi, K.-H. Joeckel

\section{Saturday November 25th}

Keynote 3:

Eric Souetre: Healthcare and the Growing Need for Connectivity

Oral 5: Telemedecine 2:

op58 Visually Lossless Image Compression for Teleradiology

W. Stefanon, D. Auer, M. Grobovschek, L. Auer

op03 Virtual sonography in Internet

J. Vilarchao-Cavia, O. Ferrer-Roca, M. Clavijo, J.M. Troyano

op77 Telemedicine and Elderly Care: Towards an Internet Blood Pressure Monitoring System J.S. Briggs, C.J. Fitch, R.A. Beresford

op78 Applying the 3-D Wavelet Transform to Transmit Medical Video in Telemedicine G. Bernabé, J. González, J. García, J. Duato 
op80 XML Technology in Support of Clinical Protocols for Teleconsultation 207 C.E. Chronaki, P. Lelis, M. Tsiknakis, S.C. Orphanoudakis

op89 TeleCardio-FBC: an Application of Telemedicine for Cardiology

K. Villela, M. Montoni, J. Blaschek, A. Rocha, A. Rabelo Jr.

Oral 6: Clinical Applications 2:

op39 Healthcare Scheduling in the Internet Age - New Forms of Healthcare Delivery H. Schellens

op23 Interactive Medical Web Sites for Children and Teenagers A. Robert, M.D. Pretlow

op61 SNOMED RT: an International Terminology Infrastructure for Clinical Internet

Applications

D. Aschman

op69 The Medical Practice Website

J.W. Van der Slikke, L. Loimer

op33 Comparing Paper-based vs. Internet-/Handheld-Based Clinical Trial Coordination in a Study on Hernia inguinalis: How good is Cost/Benefit Ratio? C.H. Elsner, M. Egbring, A. Wolf, A. Merz, H. Kottkamp, G. Hindricks

op15 Evaluation of the Patient Internet Cafe at Rouen University Hospital M. Douyère, K. Böer, I. Sanchez, S.J. Darmoni

Keynote 4:

Bill Silberg: The Web as a Global Medical Information Tool: Opportunities and Challenges

Oral 7: Medical Records:

op19 Internet Patient Records: New Techniques

S. Moehrs, G. Brelstaff, P. Anedda, G. Zanetti, M. Tuveri

op25 A Web-Based Electronic Medical Record System, Based upon the GEHR-Architecture

P. Hendrickx, F. Verbeke

op36 DNS/Hostmaster Architecture in the Greek Network of Healthcare and Welfare Services

P. Lampsas, A. Vagelatos, D. Sofotassios, C. Papanikolaou

op38 A Clinical Internet Trial Management System - Citmas

K. Nelausen, H.H. Hansen

op50 An Infrastructure for Integrated Electronic Health Record Services: The Role of XML

D. Katehakis, S. Sfakianakis, M. Tsiknakis, S. Orphanoudakis

op66 Structured Data Management and Electronic Communication for Internet Based Virtual Health Record Environment P. Sweeney

op73 Internet \& Electronic Medical Records in Dutch Burn Care Unit P. Doupi 
Oral 8: Portal Sites and Legal Issues:

op07 Internet of Dublin Core Metadata in CISMeF, a Structured Health Resource Guide on the Internet

B. Thirion, S.J. Darmoni, J.P. Leroy, M. Douyère, J. Piot

op55 The Use of Internet for Health Purposes in Brazil

R.F. Bruns, J.S. Dias, E.R. Sbrissia, L.E.A.M. Martins, F.V. Rocha

op75 Redesign of the Virtual Medical Community Portal Site - Experiences with Application and Integration of XML/XSLT Software

A. Emmen, L. Versweyveld

op81 Patients-Online: First-Hand Knowledge — from Patient to Patient. First Experiences with the Austrian Prototype (www.patients-online.at)

H. Ebner, M. Muellner, R. Ernst, K. Schuetz-Mueller

op93 Internet-Based Health Information System for Indonesian Decentralised Health Services A. Fuad, L. Trisnantoro, J. Jeugmans

op72 Ethical Codes for Internet Health Information - Consensus in the Horizon?

K. Lampe, P. Doupi

op97 A Software Agent for Systemic Retrieval of Medical Information from the Internet P.A. Kokkinidis, L.P. Gatsoris, A.E. Germenis

Poster 3:

po31 Moderating Rhythmologic Topics over the Internet: a First Years Experience at the Heart Center Leipzig

C. Elsner, G. Hindricks, M. Egbring, H. Kottkamp

po65 Integrating MedFrame Databases in the MediMedia Medical Image European Network F. Barbini, A. D'Atri, V. Mauro, G. Zini, B. Zobel

po40 Internet as a "Transparent" Management Tool. First Experience in a National Institute of Health and Social Services in Argentina

A. Melamud, R. Altrudi, R. Herrero, E. Rodas, G. Martín

po16 In Vitro Diagnostic Net E-Marketing for Life Science (http://www.ivd-net.com) M. Dressel

po24 How to Neutralize Healthcare Professionals' Fear of E-Health: a Simulated Patient eCare Project C.M. Stock

po32 Attitude towards Gaining Medical Information in Mideuropean Population First Results A. Wolf, G. Hindricks, M. Egbring, D. Sem, C. Elsner

Poster 4:

po35 S.O.S. - Sustaining Oncology Studies: a Comprehensive Website in Oncology W. Horn, A. Colacci, F. Molina, L. Motta, L. Santi

po43 Use of an Intranet-Based Electronic Patient Record System in Laser Medicine A. Daskalaki, A. Lazakidou, C. Philipp, C. Jacob, H.-P. Berlien

po70 Medical Informatics \& The Internet / Viewpoint from an Outpatient Clinical Center L. Lambrecht, L. Vandecaveye, X. Goemanne, J. Stas, A. Van Olmen, C. De Mil

po71 The Production of an On-line Medical Textbook J. Spafford, H. Goepfert 
po86 Clinical Quality Guidelines in a Lotus Notes Based Intranet

\section{Sunday November 26th}

T7 How to Use Pretty Good Privacy (PGP)

T8 Health Information Europortal Tutorial

T9 WEB PACS Application of Web Technology for Distributing Digital Images in and outside a Hospital

By J. Schillebeeckx, E. Ranschaert 